\title{
Influences of Attachment Style, Family Functions and Gender Differences on Loneliness in Japanese University Students
}

\author{
Akihito Fujimori'1, Hideki Hayashi' ${ }^{1}$, Yoji Fujiwara², Taisuke Matsusaka ${ }^{3}$ \\ ${ }^{1}$ Kawasaki University of Medical Welfare, Okayama, Japan \\ ${ }^{2}$ Takahashi, Okayama, Japan \\ ${ }^{3}$ Manaboshi Clinic, Okayama, Japan \\ Email: fujimori@koto.kpu-m.ac.jp
}

How to cite this paper: Fujimori, A., Hayashi, H., Fujiwara, Y., \& Matsusaka, T. (2017). Influences of Attachment Style, Family Functions and Gender Differences on Loneliness in Japanese University Students. Psychology, 8, 654-662. https://doi.org/10.4236/psych.2017.84042

Received: January 24, 2017

Accepted: March 28, 2017

Published: March 31, 2017

Copyright $\odot 2017$ by authors and Scientific Research Publishing Inc. This work is licensed under the Creative Commons Attribution International License (CC BY 4.0).

http://creativecommons.org/licenses/by/4.0/

\begin{abstract}
Psychological studies of loneliness are comparatively new. This study examined influences of attachment style, family functions and gender differences on loneliness in Japanese university students. The following questionnaires were administered: University of California at Los Angeles (UCLA) Loneliness Scale, Internal Working Model Scale for assessing attachment, and Family Adaptability and Cohesion Evaluation Scale III. Stepwise multiple regression analyses were employed to examine relationships between loneliness as the dependent variable, and gender, attachment style and family functions as independent variables. Results showed that gender differences significantly influenced loneliness. Furthermore, loneliness was positively influenced by avoidant and ambivalent attachment styles and negatively influenced by stable attachment style and family cohesion. A significant interaction was also observed between secure attachment style and family cohesion. These results indicated that a stable attachment style might reduce loneliness. On the other hand, in spite of an unstable attachment style, loneliness can be decreased if family cohesion is high.
\end{abstract}

\section{Keywords}

Loneliness, Attachment Style, Family Functions, Family Cohesion, Gender Differences

\section{Introduction}

Psychological studies of loneliness are comparatively new. Peplau \& Perlman (1982) defined loneliness as an unpleasant emotional experience that stems in 
some important ways from inadequate social relationships. Early studies (John \& John, 1999) suggested that loneliness is associated with situational factors, which could mean changing situations, and with personal factors related to loneliness. In other words, loneliness is an emotion in which, although they hope to, people cannot link to others.

Furthermore, it must be noted that during adolescence, loneliness is universal. In adolescence, the parent-child relationship changes in character and the adolescent's identity is formed. Blos (1967) named this "the second individuation process". Characteristically, adolescents begin to spend less time with their parents (Larson et al., 1996), closeness with their parents declines (Holmbeck, 1996) and they receive less social support from their parents (Furman \& Buhrmester, 1992). During that process, adolescents typically feel a strong sense of loneliness. In addition, Hirosawa (2002) indicated that in Japanese university students, loneliness included four feelings, namely, "self-pity", "broken-hearted", "despair" and "irritation". These feelings were significantly higher in females than in males.

With these issues in mind, we examined the association between loneliness and psychological or psychiatric problems. Loneliness can give rise to various difficulties, including juvenile delinquency (Brennan \& Auslander, 1979), dependence on alcohol (Nerviano \& Gross, 1976), dependence on parasocial relationships such as social net-working sites (Baek et al., 2013), depression (Leiderman, 1969; Ortega, 1969) and suicide attempts (Jacobs, 1971; Wenz, 1977).

Thus, reducing loneliness to help remedy psychological or psychiatric problems is important. Additionally, parental and family factors of loneliness as causes of such problems must be examined. John \& John (1999) indicated that chronic feelings of loneliness appear to have roots in childhood, and early attachment processes cause psychological and social problems such as low positive affect, social withdrawal, depression, and so on. For this reason, we closely examined the association between loneliness and attachment style, as well as family functions.

\subsection{Loneliness, Attachment and Family Functions}

For about half a century, attachment theory has been considered important in explaining how a person relates to others. Attachment is the instinct for an affectional bond between a child and his/her parental figure and is said to have an impact on a person's later human relationships. Secure attachment is related to adaptation and insecure attachment to maladaptation (Bowlby, 1969).

The following was referred to in Fujimori et al. (2015) about attachment theory. Bowlby (1969) believed that attachment behaviours are instinctive, activated by any conditions that appear to threaten the achievement of proximity, such as separation, insecurity and fear. Attachment behaviours are then transferred to different relationship partners throughout the life span. Moreover, he suggested the Internal Working Model (IWM) concept as the foundation for understanding how attachment processes operate throughout a person's life. 
IWM develops in the context of primary caregivers during childhood and then generalizes to other types of social relationships during adulthood. Later, Ainsworth a\& Bell (1970) classified three IWM styles: avoidance (type A), secure (type B) and ambivalent (type C). They concluded that these attachment styles resulted from a child's early interactions with the caregiver. While investigating the environment, Type A people do not orient themselves to their attachment figure. They are very independent from the attachment figure both physically and emotionally. The attachment figure may withdraw from helping during their difficult tasks and often be unavailable during times of emotional distress. Type B people feel confident that the attachment figure will be available to meet their needs. They use the attachment figure as a safe base for exploring the environment and seek the attachment figure in times of distress. Type $\mathrm{C}$ people adopt an ambivalent behavioural style toward the attachment figure. They commonly exhibit clingy and dependent behaviour, but reject the attachment figure when they engage in interaction. Accordingly, they exhibit difficulty moving away from the attachment figure to explore new surroundings. When they are distressed, soothing them is difficult and they are not comforted by interaction with the attachment figure. This behaviour results from an inconsistent level of response to their needs from the primary caregiver.

In general, there might be family functions issue or an attachment problem in addiction, substance abuse or conduct disorder conditions. In the area of alcoholism, Mothersead et al. (1998) suggested that as the level of family dysfunction increases, secure attachment decreases.

Although loneliness necessarily increases in adolescents, some studies have indicated a positive aspect of this. Winnicott (1958) originated the notion "Capacity to Be Alone", which means internal security formed in childhood. So obtaining this capacity before adolescence may decrease an individual's negative sense of loneliness. Thus, attachment style and family functions are important in loneliness. But the relationship among loneliness, attachment style and family functions has not yet been studied and little attention has been paid to gender differences in the influence on loneliness of attachment style and family functions. Therefore, this study focuses on these factors' impact on loneliness.

\subsection{The Present Study}

We believe that attachment style and family functions may help further explain loneliness. Thus, with Japanese university students as participants, the present study examines the influence of attachment style, family functions and gender differences on loneliness.

\section{Methods}

\subsection{Sample}

The current survey study was conducted at Hanazono University in Japan, and the university's students were our subjects. We told all participants that their responses would be kept confidential and that only summary information would 
be presented. Furthermore, we assured them of complete anonymity. Overall, 284 students (males 130, females 154), aged from 18 to 29 (SD 1.2), volunteered to participate in our study. To prevent any leaking of personal information via survey assistants, participants responded anonymously to survey materials. The Ethical Review Committee of Kawasaki University of Medical Welfare approved this study (Approval No. 15-041).Over and above, this study was conducted at the same time with Fujimori et al. (2015) and investigated SNSs addiction. Thus, measurements of loneliness and attachment as well as sample were duplicates.

\subsection{Measurements}

\subsubsection{Loneliness}

Participants completed the revised University of California at Los Angeles (UCLA) Loneliness Scale to evaluate loneliness. This scale, developed by Russell (1982), comprises 20 items scored on a four-point scale. The Japanese version's reliability $(\alpha=0.87)$ and validity were confirmed by Moroi (1992).

\subsubsection{Attachment Style}

To assess individual differences in attachment style, participants completed the Japanese translation version of the Internal Working Model Scale (IWMS; Toda, 1988), which was based on the Adult Attachment Scale (Hazan \& Shaver, 1987). This instrument measures 18 items scored on a six-point scale that includes three factors with six items each. The Avoidant Attachment subscale assesses a person's feeling that others reject him/her and that the person cannot expect the others' support $(\alpha=0.74)$. The Secure Attachment subscale assesses a person's feeling that he/she values the presence and support of others and that others are responsive to him/her $(\alpha=0.91)$. The Ambivalent Attachment subscale assesses a person's ambivalent feelings of trust in and distrust toward others and strong feelings of self-insufficiency ( $\alpha=0.82$ ). Overall, each factor showed good reliability in the Japanese version. This scale captures three factors as characteristics and measures individual differences in IWM by relative comparison.

\subsubsection{Family Functions Style}

The Family Adaptability and Cohesion Evaluation Scales III (FACESIII; Kusada, 1995) was used to assess family functions style. FACESIII was developed by Olson et al. (1985) to assess the two factors of Cohesion and Adaptability. Cohesion indicates emotional linking. An extremely high or low score indicates family dysfunction, while a middle score indicates adequate family function. This factor's reliability was confirmed in the Japanese version $(\alpha=0.88)$. Adaptability indicates that flexibility varies appropriately, according to situations, for instance, if the family were endangered by a disease, a school's rejection and so on. Good reliability was confirmed in the Japanese version $(\alpha=0.74)$, which consists of 20 items scored on a five-point scale.

\subsection{Statistical Analysis}

First, a Pearson correlation coefficient was performed in the overall sample pre- 
liminary analysis.

Then, multiple regression analyses were performed to examine the relationship between loneliness as the dependent variable and gender, attachment style and family functions as independent variables. All analyses were performed using SPSS (version 17.0) for Windows (SPSS Inc., Chicago, IL, USA).

\section{Results}

\subsection{Preliminary Analysis}

Descriptive information on measures used in this study is presented in Table 1. We conducted several preliminary analyses to determine attachment style (avoidant, secure and ambivalent), family functions (Cohesion and Adaptability) and loneliness, as well as to compare participants' gender and age by t-tests. Results showed that males and females differed in secure attachment style $(p<$ $0.05)$ and loneliness $(p<0.01)$. However, age showed no significant difference except for ambivalent attachment style $(p<0.05)$. These results indicated that males reported more loneliness than females. Different structures in attachment style were significantly higher in females than in males, especially in secure attachment.

\subsection{Relevance among Attachment Style, Family Functions, and Loneliness}

Next, bivariate associations among variables were estimated using Pearson product-moment correlations. All factors among attachment style, family functions and loneliness correlated significantly (Table 2). On the whole, for family functions, loneliness was positively correlated with avoidant attachment style ( $r$ $=0.45, p<0.01)$ and ambivalent attachment style $(r=0.26, p<0.01)$. Loneliness was negatively correlated with secure attachment style $(r=-0.56, p<0.01)$, cohesion $(r=-0.36, p<0.01)$ and adaptability $(r=-0.34, p<0.01)$. These results indicate that loneliness is associated with attachment style and family functions.

Table 1. Descriptive statistics and results of independent t-test comparing gender and age $(\mathrm{N}=284)$.

\begin{tabular}{|c|c|c|c|c|c|}
\hline & \multicolumn{3}{|c|}{ Basic Statistic } & \multicolumn{2}{|c|}{ Preliminary Analysis } \\
\hline & Mean & SD & Range & Sex $t$ & Age $r$ \\
\hline \multicolumn{6}{|l|}{ Attachment Style } \\
\hline Avoidant & 18.99 & 5.10 & $6-35$ & -0.52 & 0.06 \\
\hline Secure & 21.37 & 6.04 & $6-36$ & $-2.10^{*}$ & 0.03 \\
\hline Ambivalent & 21.65 & 5.51 & $6-36$ & -1.36 & $-0.18^{\star}$ \\
\hline \multicolumn{6}{|l|}{ Family Function } \\
\hline Cohesion & 29.96 & 8.15 & $10-50$ & $-3.62^{\star *}$ & 0.00 \\
\hline Adaptability & 28.15 & 5.58 & $13-45$ & $-2.75^{\star \star}$ & 0.05 \\
\hline Lonelieness & 38.71 & 9.28 & $20-74$ & $3.77^{\star *}$ & -0.03 \\
\hline
\end{tabular}

Note: ${ }^{\star} p<0.05,{ }^{* *} p<0.01$. 


\subsection{Influence of Attachment Style, Family Functions and Gender Differences on Loneliness}

Based on the results above, stepwise multiple regression analyses were employed to examine the relationship between loneliness as the dependent variable and gender, attachment style and family functions as independent variables (Table $3)$. In the first step of analysis, gender was included. Results showed that gender differences significantly influenced loneliness $(p<0.01)$. That is, in this study, males reported more loneliness than females. The second step added attachment style (Avoidant, Secure and Ambivalent). Results showed that on loneliness, Avoidant $(p<0.01)$ and Ambivalent $(p<0.05)$ attachment styles had significant negative influences and Secure $(p<0.01)$ attachment style had positive significant influence. In the third step, Family Functions were added. Results showed

Table 2. Partial correlations in attachment style, family functions and loneliness $(\mathrm{N}=$ 284).

\begin{tabular}{|c|c|c|c|c|c|c|}
\hline & \multicolumn{3}{|c|}{ Attachment Style } & \multicolumn{2}{|c|}{ Family Function } & \multirow[b]{2}{*}{ Loneliness } \\
\hline & Avoidant & Secure & Ambivalent & Cohesion & Adaptability & \\
\hline Avoidant & - & & & & & \\
\hline Secure & $-0.14^{*}$ & - & & & & \\
\hline Ambivalent & $0.24^{* *}$ & $-0.14^{\star}$ & - & & & \\
\hline Cohesion & $-0.14^{*}$ & $0.29^{\star *}$ & $-0.12^{*}$ & - & & \\
\hline Adaptability & $-0.16^{\star *}$ & $0.29^{\star *}$ & $-0.24^{* *}$ & $0.65^{* *}$ & - & \\
\hline Lonelieness & $0.45^{* *}$ & $-0.56^{* *}$ & $0.26^{* *}$ & $-0.36^{* *}$ & $-0.34^{* *}$ & - \\
\hline
\end{tabular}

Note: ${ }^{\star} p<0.05,{ }^{* *} p<0.01$.

Table 3. Multiple regression results predicting loneliness by gender, attachment style and family functions $(\mathrm{N}=284)$.

\begin{tabular}{|c|c|c|c|c|}
\hline & \multicolumn{4}{|c|}{$\operatorname{adj} \beta$} \\
\hline & Step 1 & Step 2 & Step 3 & Step 4 \\
\hline 1) Gender & $0.22^{* *}$ & $0.14^{* *}$ & $0.11^{\star *}$ & $0.12^{* *}$ \\
\hline \multicolumn{5}{|l|}{ 2) Attachment Style } \\
\hline Avoidant & & $0.35^{* *}$ & $0.33^{* *}$ & $0.33^{* *}$ \\
\hline Secure & & $-0.49^{* *}$ & $-0.44^{* *}$ & $-0.45^{* *}$ \\
\hline Ambivalent & & $0.10^{*}$ & $0.09^{*}$ & $0.08^{*}$ \\
\hline \multicolumn{5}{|l|}{ 3) Family Function } \\
\hline Cohesion & & & $-0.14^{\star}$ & $-0.13^{*}$ \\
\hline Adaptability & & & -0.04 & -0.06 \\
\hline \multicolumn{5}{|l|}{ 4) Interaction } \\
\hline Attachment style $\times$ Family Functions & & & & Secure $\times$ Cohesion $=0.11^{\star}$ \\
\hline$R^{2}$ & 0.05 & 0.49 & 0.52 & 0.53 \\
\hline
\end{tabular}

Note: ${ }^{*} p<0.05,{ }^{* *} p<0.01$. 
that loneliness was negatively influenced by family cohesion $(p<0.05)$. On the contrary, adaptability showed no significant influence on loneliness. In the fourth step, a significant interaction was observed between secure attachment type and family cohesion $(p<0.05)$. The full model (step 4$)$ accounted for 53\% of variance in loneliness.

\section{Discussion}

This is the first study to examine the influence of attachment style, family functions and gender difference on loneliness in Japanese university students. Findings generally showed that loneliness was influenced by attachment style and family functions as well as gender.

Preliminary analysis indicated that males had significantly higher loneliness. This result differs from earlier studies' results, which reported that loneliness was significantly higher in females than in males (Hirosawa, 2002). This difference may be due to the influence of secure attachment and family functions. Males were also significantly lower in the previously discussed factors in this study. However, no research was conducted on the influence of attachment and family functions in Hirosawa's study. If we could recruit more males with secure attachment style and stable family function, results would of course differ. In stepwise multiple regression analyses, after attachment style was added (after step 2), the coefficient of determination $\left(R^{2}\right)$ rose rapidly. Thus, this study's results implied that attachment style and family functions (cohesion only) had more influence on loneliness than gender difference.

Furthermore, we found that secure attachment style and family cohesion might reduce loneliness, although avoidant and ambivalent attachment types increase loneliness. These results might indicate how important it is that a child forms stable attachment relationships with parents/caregivers. In other words, such relationships might prevent mental problems caused by loneliness.

Another key finding was that significant interaction might account for the fact that in spite of an unstable attachment style (avoidant or ambivalent), loneliness could decrease if family cohesion is high $(\beta=0.11, p<0.05)$. On the other hand, cohesion had no significant influence on loneliness if secure attachment was high $(\beta=-0.05, \mathrm{~ns})$. This result also indicated that secure attachment was more important than present family functions. In recent years in Japan, over $40 \%$ of university students have lived apart from parents/caregivers. Thus, it might be important that university students with an unstable attachment type, but high family cohesion avoid living alone if possible. To put it more concretely, adaptation after entrance to university could be predicted by investigating family functions, attachment style and loneliness before university admission.

The current study has several important limitations. First, we must examine loneliness itself more carefully because it includes various aspects, for instance, situational factors, interpersonal factors, adolescents' state of mind and so on. Thus, in a future study, we will investigate various aspects of loneliness. Moreover, what must not be forgotten is that other individual psychological factors 
influence loneliness.

\section{References}

Ainsworth, M., \& Bell, S. (1970). Attachment, Exploration, and Separation: Illustrated by the Behavior of One-Year-Olds in a Strange Situation. Child Development, 41, 49-67. https://doi.org/10.2307/1127388

Baek, Y., Bae, Y., \& Jang, H. (2013). Social and Parasocial Relationships on Social Network Sites and Their Differential Relationships with Users' Psychological Well-Being. Cyberpsychology, Behavior, and Social Networking, 16, 512-517. https://doi.org/10.1089/cyber.2012.0510

Blos, P. (1967). The Second Individuation Process of Adolescence. Psychoanalytic Study of the Child, 22, 162-186.

Bowlby, J. (1969). Attachment: Attachment and Loss Volume One. New York: Basic Books.

Brennan, T., \&Auslander, N. (1979). Adolescent Loneliness: An Exploration Study of Social and Psychological Pre-dispositions and Theory. Boulder, CO: Behavioral Research Institute.

Fujimori, A., Yamazaki, T., Sato, M., Hayashi, H., Fujiwara, Y., \& Matsusaka, T. (2015). Study on Influence of Internal Working Models and Gender Differences on Addiction of Social Network Sites in Japanese University Students. Psychology, Special Issues, Research on Applied Psychology, 6, 1832-1840. https://doi.org/10.4236/psych.2015.614179

Furman, W., \& Buhrmester, D. (1992). Age and Sex Differences in Perceptions of Networks of Personal Relationships. Child Development, 63, 103-115. https://doi.org/10.2307/1130905

Hazan, C., \& Shaver, P. (1987). Romantic Love Conceptualized as an Attachment Process. Journal of Personality and Social Psychology, 52, 511-524. https://doi.org/10.1037/0022-3514.52.3.511

Hirosawa, T. (2002). The Influences of Loneliness and Tolerance to Aloneness on Feelings and Coping Behaviors When Lonely. Kansai University of International Studies, 3, $81-96$.

Jacobs, J. (1971). Adolescent Suicide. New York: Wiley.

John, E., \& John. C. (1999). Lonely Hearts: Psychological Perspectives on Loneliness. Applied and Preventive Psychology, 8, 1-22. https://doi.org/10.1016/S0962-1849(99)80008-0

Kusada, H. (1995). The Reliability and Validity of FACES III for Japanese. Japanese Journal of Counseling Science, 28, 154-162.

Larson, R. W., Richards, M. H., Moneta, G., Holmbeck, G., \& Duckett, E. (1996). Changes in Adolescents' Daily Interactions with Their Families from Ages 10 to 18: Disengagement and Transformation. Developmental Psychology, 32, 744-754. https://doi.org/10.1037/0012-1649.32.4.744

Leiderman, P. (1969). Loneliness: A Psychodynamic Interpretation. International Psychiatry Clinics, 6, 155-174.

Moroi, K. (1992). Dimensions of the Revised UCLA Loneliness Scale. Faculty of Humanities and Social Sciences, 42, 23-51.

Mothersead, P., Kivlighan, D., \&Wynkoop, T. (1998). Attachment, Family Dysfunction, Parental Alcoholism, and Interpersonal Distress in Late Adolescence: A Structural Model. Journal of Counseling Psychology, 45, 196-203. 
https://doi.org/10.1037/0022-0167.45.2.196

Nerviano, V. J., \& Gross, W. F. (1976). Loneliness and Locus of Control for Alcoholic Males: Validity against Murray Need and Cattell Trait Dimensions. Journal of Clinical Psychology, 32, 479-484. https://doi.org/10.1002/1097-4679(197604)32:2<479::AID-JCLP2270320260>3.0.CO;2$\underline{\mathrm{B}}$

Olson, D., Portner, J., \&Lavee, Y. (1985). FACES III Manual. Twin Cities, Minnesota: University of Minnesota.

Ortega, M. J. (1969). Depression, Loneliness and Unhappiness. In E. Schneidman, \& M. J. Ortega (Eds.), Aspects of Depression (pp. 143-153). Boston, MA: Little Brown.

Peplau, A., \& Perlman, D. (1982). Loneliness: A Sourcebook of Current Theory, Research, and Therapy. New York: John Wiley \& Sons.

Russell, D. (1982). The Measurement of Loneliness. In L. Peplau, \& D. Perlman (Eds.), Loneliness: A Sourcebook of Current Theory, Research and Therapy (pp. 81-104). New York: John Wiley \& Sons.

Toda, K. (1988). Basic Interpersonal Relationships and Attachment Style in the Late Adolescence-Examination from Working Models. In 52nd Conference of the Japanese Psychological Association (p. 27). Hiroshima: Japanese Psychological Association.

Wenz, F. V. (1977). Seasonal Suicide Attempts and Forms of Loneliness. Psychological Reports, 40, 807-810. https://doi.org/10.2466/pr0.1977.40.3.807

Winnicott, D. W. (1958). The Capacity to Be Alone. International Journal of Psycho-Analysis, 39, 416-420.

\section{Submit or recommend next manuscript to SCIRP and we will provide best service for you:}

Accepting pre-submission inquiries through Email, Facebook, LinkedIn, Twitter, etc. A wide selection of journals (inclusive of 9 subjects, more than 200 journals)

Providing 24-hour high-quality service

User-friendly online submission system

Fair and swift peer-review system

Efficient typesetting and proofreading procedure

Display of the result of downloads and visits, as well as the number of cited articles

Maximum dissemination of your research work

Submit your manuscript at: http://papersubmission.scirp.org/

Or contact psych@scirp.org 